\title{
A cloud-to-ground lightning climatology for north-eastern Italy
}

\author{
L. Feudale, A. Manzato, and S. Micheletti \\ OSMER - Osservatorio Meteorologico Regionale dell' ARPA FVG, Visco (UD), Italy \\ Correspondence to: L. Feudale (laura.feudale@meteo.fvg.it)
}

Received: 8 January 2013 - Revised: 30 April 2013 - Accepted: 6 May 2013 - Published: 6 June 2013

\begin{abstract}
This study analyzes the spatial distribution and temporal characteristics of cloud-to-ground lightnings $(\mathrm{C} 2 \mathrm{G})$ in the North East of Italy and the neighboring areas of Austria, Slovenia and Croatia. The dataset consists of about 6.5 millions C2G flash records, both positive and negative, observed between January 1995 and December 2011 by the "Centro Elettrotecnico Sperimentale Italiano-Sistema Italiano Rilevamento Fulmini” (CESI/SIRF), part of the European Cooperation for Lightning Detection (EUCLID) Network.

The results show that $\mathrm{C} 2 \mathrm{G}$ lightnings concentrate in the foothill regions on the southern flank of the Eastern Alps with a maximum of discharge frequency of 10 lightnings per $\mathrm{km}^{2}$ per year. The number of $\mathrm{C} 2 \mathrm{G}$ strokes varies with the period of the year: the most active period for lightning starts in April and lasts through November with the highest number of $\mathrm{C} 2 \mathrm{G}$ strokes happening during the summer months of July and August, with maximum spatial density slightly moving from the mountain to the coastal area. The least frequency of C2G strokes is observed during wintertime. The mean diurnal C2G lightning activity for the whole domain shows a peak around 16:00-17:00 UTC and reaches a minimum around 07:00-09:00 UTC; the mean spatial distribution follows different patterns depending on the period of the day.
\end{abstract}

\section{Introduction}

Lightning are one of the most fascinating weather phenomena yet still not completely understood. They usually occur in thunderstorms during a breakdown of electrical fields in the form of cloud-to-cloud and cloud-to-ground (C2G) discharges. C2G lightning is among the major causes of weather-related fatalities. In the United States, for example, some studies assert that $\mathrm{C} 2 \mathrm{G}$ lightning events contribute to a higher number of fatalities than tornadoes, hurricanes and strong winds (Ashley and Gilson, 2009); among all thunderstorm-related phenomena, only floods have recorded more average annual fatalities (Curran et al., 2000). Lightning flashes may cause also major property damage, power system breakdowns and forest fires (Rorig and Ferguson, 1999). Therefore lightning spatial distribution becomes of great interest, especially for energy-management and safety purposes. Furthermore, as our society is becoming more and more dependent on information networks, the knowledge of lightning prone areas could help in protecting informatic systems from disruption due to lightning discharges.

OSMER is particularly interested in studying the lightning climatology, because the Eastern Alps have a maximum in lightning spatial density, as it is seen in Schulz et al. (2005) and it will be proved later in this work. For this purpose, this study gives a detailed analysis of the spatial frequency of lightning considering the north-eastern Italy domain and interprets the observed structures in relation with the characteristics of this area. In addition, the frequency of lightning flashes provides a measure of the frequency of intense convection, identifying the areas more prone to severe weather events. The knowledge of lightning distribution may be used as a predictor into very complex weather nowcasting systems, as the system developed in the INCA-CE project (Haiden et al., 2011), and in particular the lightning climatology in terms of thunderstorm probability distribution may give a contribution to nowcasting and alerting in case of severe weather events, such as strong thunderstorms. 
In the following sections, data and results regarding both spatial and temporal analysis of $\mathrm{C} 2 \mathrm{G}$ lightning distribution in the target area are discussed. Then, it follows the conclusions.

\section{Data}

The $\mathrm{C} 2 \mathrm{G}$ lightning data used in this analysis are provided by the "Centro Elettrotecnico Sperimentale Italiano-Sistema Italiano Rilevamento Fulmini" (CESI/SIRF, Bernardi and Ferrari, 2004), part of the European Cooperation for Lightning Detection (EUCLID) Network. The dataset consists of $\mathrm{C} 2 \mathrm{G}$ lightning records, both positive and negative, observed between January 1995 and December 2011. These measurements are obtained through a network of Vaisala sensors which detects the return stroke, usually considered the largest discharge transfer during a lightning event. Up to 1999 , the CESI/SIRF measurement network included just about 12 sensors located in the whole Italian peninsula. In 1999 four more sensors where added in order to cover the islands of Sicily and Sardinia and part of the sea between them and the mainland. Since 2000, when SIRF entered in the EUCLID Network, the lightning detection system has been strengthened by sensors in the neighboring countries of Austria, Slovenia and Switzerland. Therefore, the records between 1995 and 1999 may be affected by lower localization precision. Figure $1 \mathrm{a}$ and $\mathrm{b}$ show the $\mathrm{C} 2 \mathrm{G}$ lightning density (in lightning number per $\mathrm{km}^{2}$ per hour, multiplied by a factor of $10^{4}$ ) for the two periods characterized by a different number of lightning detection sensors: 1995-1999 in Fig. 1a and 2000-2011 in Fig. 1b. Of course, the two C2G lightning density patterns look quite different in areas far from the Italian border, that is in the areas northward (Austria and Switzerland) and eastward (Slovenia and Croatia), revealing an evident influence of the sensor distribution to $\mathrm{C} 2 \mathrm{G}$ lightning spatial distribution. Focusing inside the Italian domain (latitude: $44-47^{\circ} \mathrm{N}$, longitude: $10-14^{\circ} \mathrm{E}$ ), where, as it will be shown later, the main $\mathrm{C} 2 \mathrm{G}$ lightning activity is concentrated, the spatial correlation of these 5 contiguous years against the remnant $12 \mathrm{yr}$ has been computed. In the histogram of Fig. 2, the black bar represents the spatial correlation 1995-1999 vs. 2000-2011 C2G lightning distributions (showed in Fig. 1), which value is 0.78 . The grey bars represent the spatial correlation calculated over a running period of 5 contiguous years (starting from 2000 and going up to 2011) against the remnant $12 \mathrm{yr}$, which have a mean value of 0.88 and a standard deviation of 0.04 . So, the natural variability of these latter $5 \mathrm{yr}$ samples (grey bars of Fig. 2) does not seem to justify the low correlation found for the 1995-1999 sample period (black bar); therefore, this low correlation seems to be due also to the lower number of lightning detection sensors.

However, considering the entire available dataset of $17 \mathrm{yr}$, the effect due to the increase of the sensors number by 2000 should not affect the global results of this work. This

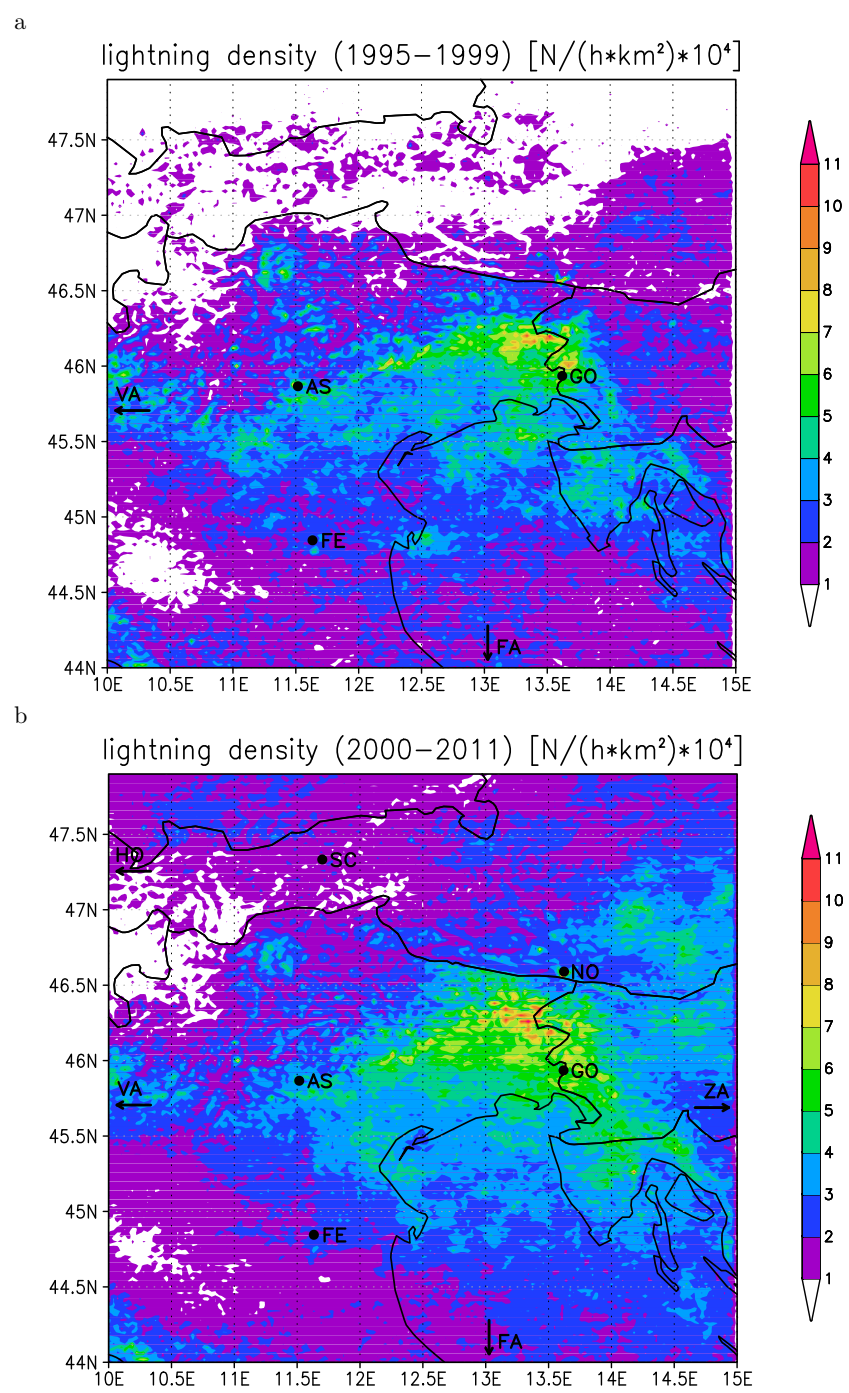

Figure 1. Lightning density and location of lightning detection sensors in the studied domain, for the period (a) 1995-1999 and (b) 2000-2011. Sensors in Italian domain: AS = Asiago, FA = Fano, $\mathrm{FE}=$ Ferrara, $\mathrm{GO}=$ Gorizia, $\mathrm{VA}=$ Varese . Sensors outside the Italian domain: $\mathrm{HO}=$ Hohenems (A), NO = Nötsch (A), SC = Schwaz (A), ZA = Zagreb (HR).

statement is supported also by Bernardi and Ferrari (2004) who showed that the CESI/SIRF network efficiency has not changed much in the northern Italy area during this transition.

The domain of interest is the area included between latitudes $44-48^{\circ} \mathrm{N}$ and longitudes $10-15^{\circ} \mathrm{E}$. The first step of the procedure is a preprocessing aimed at filtering out multiple strokes, considering as a single lightning event all the flash records reported in the same second and in the same area of $0.01 \times 0.01$ degrees. The resulting total number of lightnings is about 6.5 millions. Secondly, the data are regridded into a spatial resolution of $0.03 \times 0.02$ degrees (gridboxes covering 


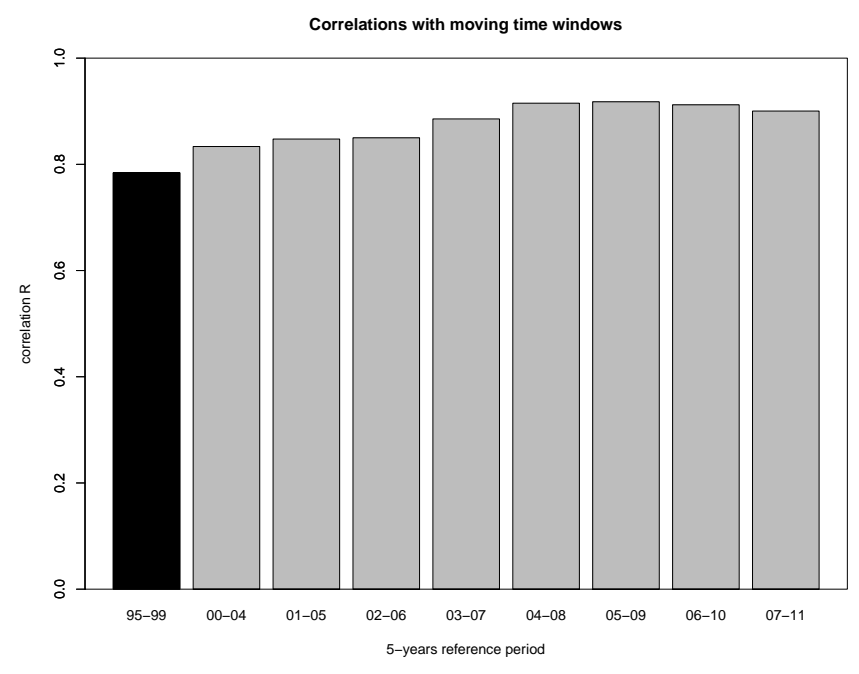

Figure 2. Histogram of spatial correlations (domain: LAT 44$47^{\circ} \mathrm{N}$, LON $10-14^{\circ} \mathrm{E}$ ) between lightning densities calculated for the $5 \mathrm{yr}$ period $1995-1999$ against the $12 \mathrm{yr}$ period $2000-2011$ (black bar), and for a running time-window period of $5 \mathrm{yr}$ (listed in the abscissa) against the remnant $12 \mathrm{yr}$ period (grey bars).

an area of about $5.15 \mathrm{~km}^{2}$ ) and aggregated in the hourly matrices, that will be analyzed in the next section.

\section{Results}

This section discusses the general characteristics of the $\mathrm{C} 2 \mathrm{G}$ lightning and how these vary in space and time. The spatial distribution of lightning was computed using all the records available in the CESI/SIRF dataset from 1995 to 2011. The map shown in Fig. 3 displays the mean number of $\mathrm{C} 2 \mathrm{G}$ lightnings per $\mathrm{km}^{2}$ per hour, multiplied by a factor of $10^{4}$. It shows that the $\mathrm{C} 2 \mathrm{G}$ lightnings are not homogeneously distributed in the domain: the maximum of $\mathrm{C} 2 \mathrm{G}$ density draws an arcshape on the southern flank of the Carnic and Julian Prealps.

\subsection{Maximum values}

Zooming on the Friuli Venezia Giulia region (FVG), a detailed analysis of the maximum density in the distribution field (Fig. 4a) reveals a peak of $17 \times 10^{-4}$ lightnings per hour per $\mathrm{km}^{2}$ in Austria, on the border with Italy, at the geographic coordinates $46.58^{\circ} \mathrm{N}$ of latitude and $13.64^{\circ} \mathrm{E}$ of longitude approximately. Evaluating in details the data, we found that this maximum corresponds to the $165 \mathrm{~m}$ high transmission antenna (Fig. 4b) on the summit of Mt. Dobratsch (2115 m a.s.1.). In fact, outliers with a high number of strokes most often correspond to locations with high towers and/or big antennas (Novák and Kyznarová, 2011). The next following maximum values in decreasing order are approximately $11.6 \times 10^{-4}, 11.3 \times 10^{-4}, 11.2 \times 10^{-4}, 10.5 \times 10^{-4}$, $10.5 \times 10^{-4}$, which correspond to the following mountains:
Gran Monte (1636 m), Matajur (1641 m), Canin (2587 m), Stol (1673 m, SLO) and Plauris (1958 m), respectively.

The relative maximum in the Eastern Alps confirms what found by Schulz et al. (2005), who analyzed the C2G lightning flashes in Austria for the $10 \mathrm{yr}$ 1992-2001. A part of north-eastern Italy, which includes the Friuli Venezia Giulia region, is on the border of their analyzed domain. They show that the activity in this small area is more than 5 flashes per year per $\mathrm{km}^{2}$, corresponding to the maximum value in their domain. This value agrees qualitatively - but not quantitatively - with our study on $17 \mathrm{yr}$ : the highest density area records about $10 \times 10^{-4}$ lightnings per hour per $\mathrm{km}^{2}$, corresponding to about 9 lightnings per year per $\mathrm{km}^{2}$.

In the following subsections the main temporal characteristics and their spatial evolution are summarized.

\subsection{Temporal statistics}

C2G lightnings show great variability in the domain from year to year, from day to day, as well as they show a diurnal cycle. To better understand the temporal characteristics of lightning activity, which is a representation of convective activity, the mean value in the studied domain of Fig. 3 is computed and analyzed with different time scales.

Figure 5a displays the mean annual value of $\mathrm{C} 2 \mathrm{G}$ frequency in the whole target domain and it shows a large variability year by year, with a maximum in 2002, having a mean value above $3.6 \times 10^{-4}$ lightnings per hour per $\mathrm{km}^{2}$ and predominant larger values towards the end of the time-series (2007-2009), indicating a possible positive trend. Nonetheless, no statistically significant trend is observed because a linear fit (dotted line) indicates a low $R^{2}(0.07)$ with a $P$ value quite high (0.29).

Other studies of lightning in the European area (Holt et al., 2001; Rivas Soriano et al., 2005; Novák and Kyznarová, 2011; Antonescu and Burcea, 2010; Finke and Hauf, 1996; Tuomi and Mäkelä, 2008), in United States (e.g. Orville and Huffines, 2001) and Australia (Kilinc and Beringer, 2007) already evidenced that $\mathrm{C} 2 \mathrm{G}$ lightning flashes occur predominantly during the warm season, as expected. Figure $5 \mathrm{~b}$ depicts the mean value of $\mathrm{C} 2 \mathrm{G}$ lightnings on a Julian Day scale; the red line is the \pm 10 day moving average, which filters higher frequency values. The active period starts approximately in April, reaches its maximum during the months of July and August (around $8 \times 10^{-4}$ lightnings per hour per $\mathrm{km}^{2}$ ) and fades thereafter until October. Some activity, even if small, is observed also during the month of November, maybe due to unstable conditions often embedded in large precipitating structures (Manzato, 2007, p. 341). Almost $90 \%$ of C2G lightning activity occurs between May and September. The minimum values are recorded during the winter months between December and February.

Figure $5 c$ shows the mean diurnal distribution of $\mathrm{C} 2 \mathrm{G}$ lightnings in the north-eastern part of Italy in hourly steps. The values follow an almost sinusoidal-like regime, with the 


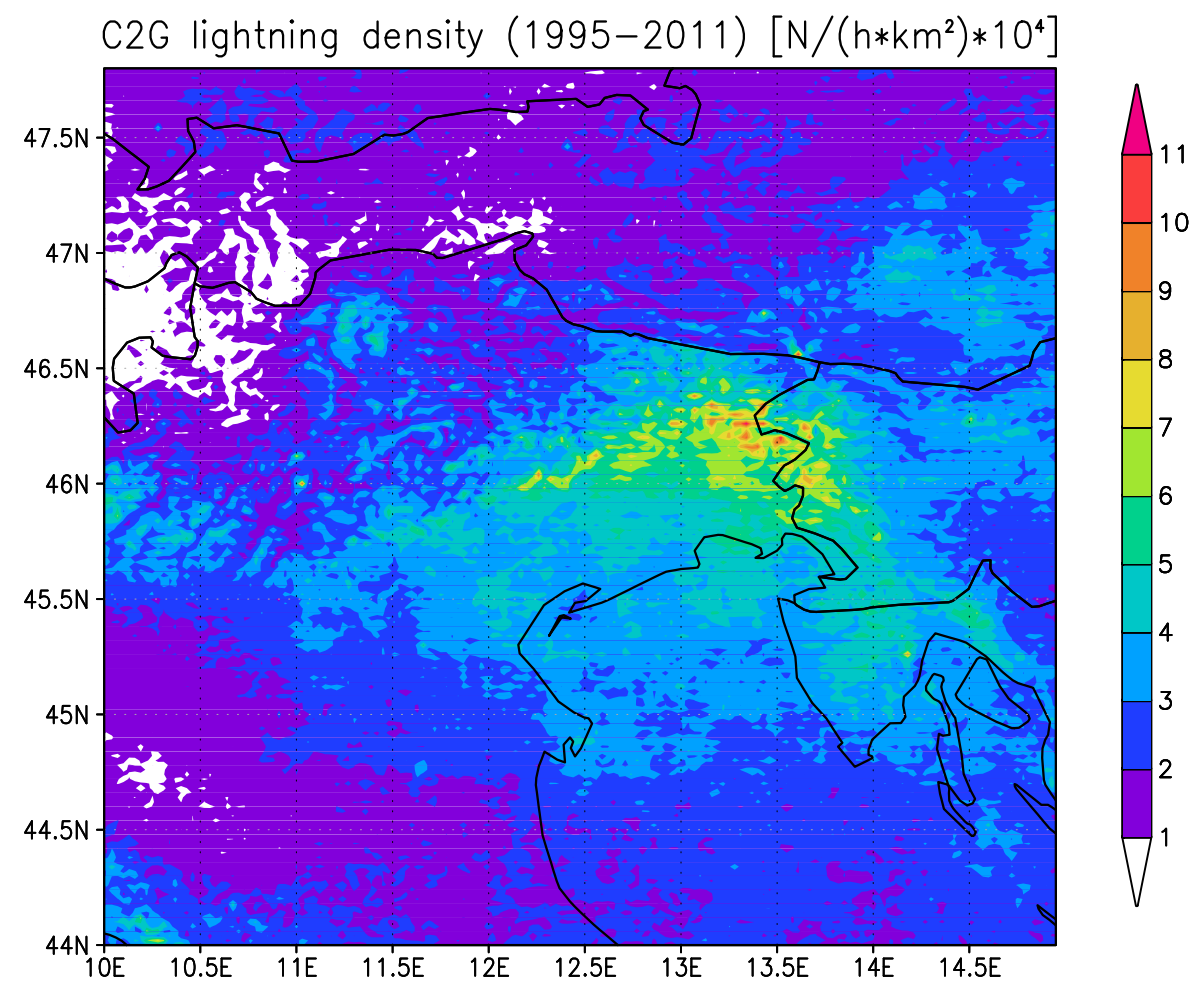

Figure 3. Spatial distribution on a grid of $0.03 \times 0.02$ degrees of resolution of the average number of $\mathrm{C} 2 \mathrm{G}$ lightning per hour per $\mathrm{km}^{2}$ computed for the $17 \mathrm{yr}$ period 1995-2011. The scale is multiplied by a factor of $10^{4}$.
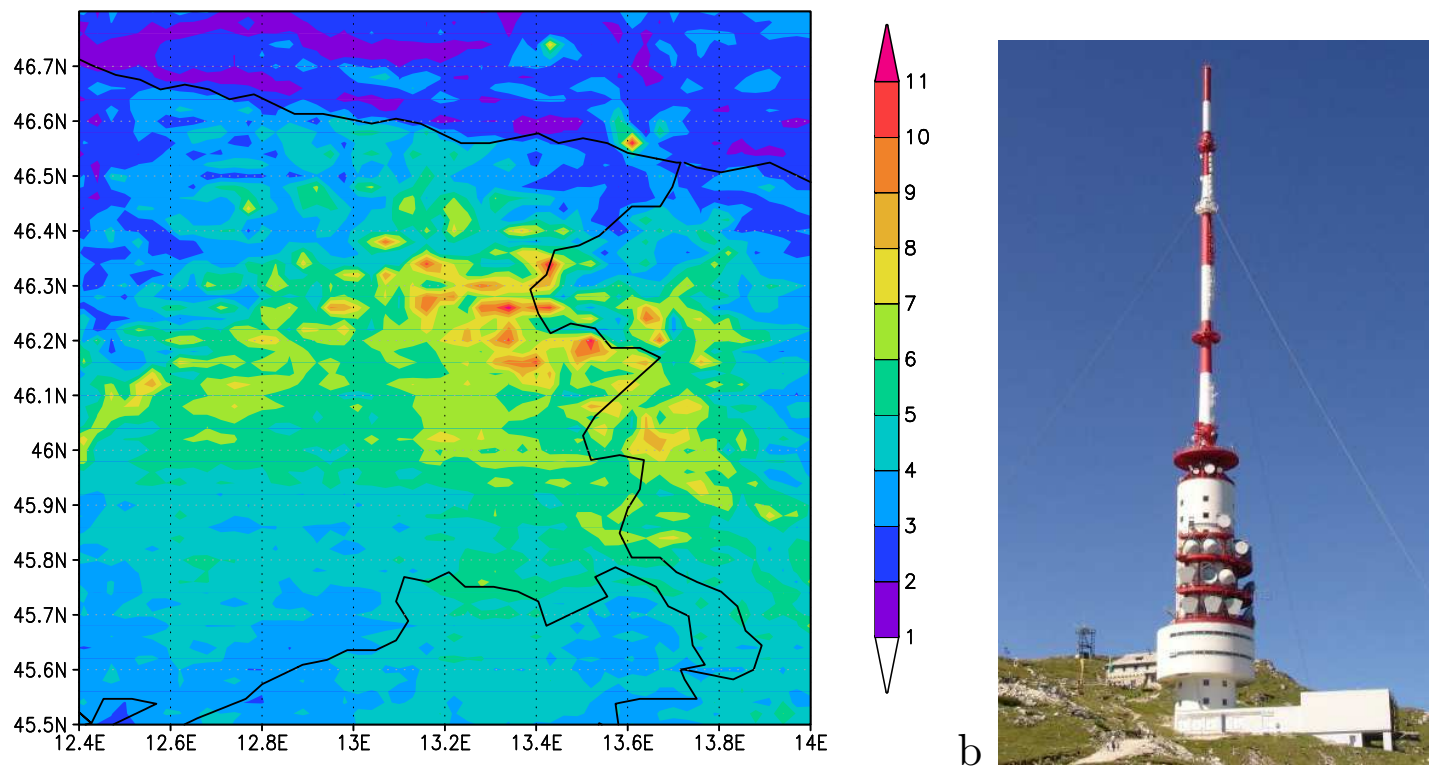

Figure 4. (a) Zoom on Friuli Venezia Giulia region of $\mathrm{C} 2 \mathrm{G}$ lightning distribution of Fig. 3 (in number of lightnings per hour per km ${ }^{2}$, multiplied by a factor of $10^{4}$ ) which shows the detection of an increased number of $\mathrm{C} 2 \mathrm{G}$ strokes at the coordinates $46.6^{\circ} \mathrm{N}$ of latitude and $13.6^{\circ} \mathrm{E}$ of longitude in the nearby Dobratsch transmitter tower in Austria shown in (b), which is a $165 \mathrm{~m}$ high tower on the Dobratsch mountain of $2115 \mathrm{~m}$ a.s.l. near Villach. 


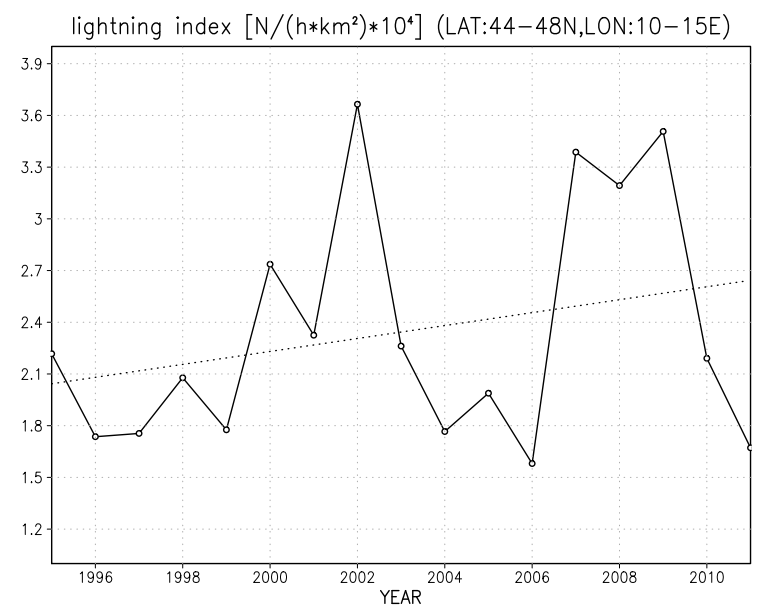

$\mathrm{b}$
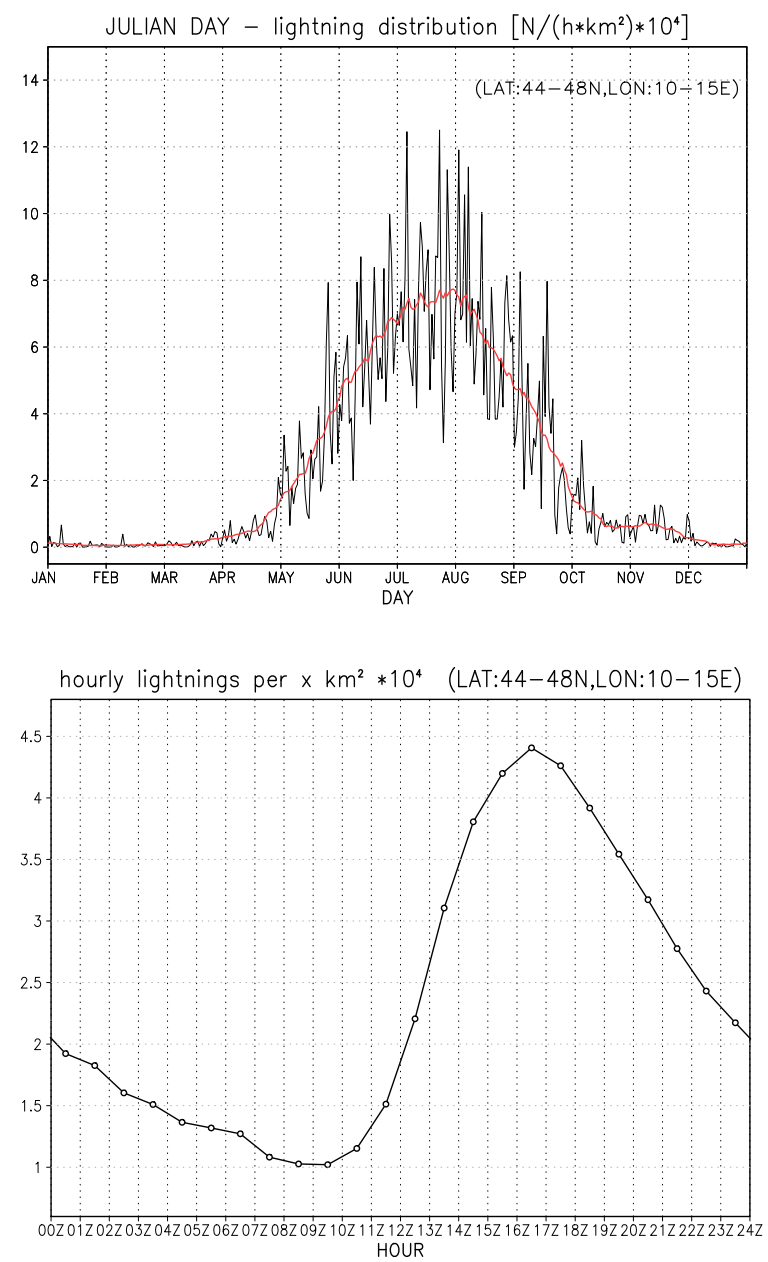

Figure 5. (a) Domain mean of $\mathrm{C} 2 \mathrm{G}$ lightning annual distribution (solid) and the $17 \mathrm{yr}$ linear trend (dotted); (b) monthly distribution of C2G lightning with the \pm 10 day moving average in red; (c) daily cycle of the $\mathrm{C} 2 \mathrm{G}$ lightning distribution in the target domain. Units are number of flashes per hour per $\mathrm{km}^{2}$ times a factor of $10^{4}$. strongest lightning activity recorded during the afternoon, with a peak between 16:00 and 17:00 UTC above $4 \times 10^{-4}$ flashes per hour per $\mathrm{km}^{2}$, and the weakest lightning activity observed during the morning hours, with minimum of $1 \times 10^{-4}$ flashes per hour per $\mathrm{km}^{2}$ between 08:00 and 10:00 UTC. The slope from the minimum to the maximum is quite steep since the rise occurs in only $6 \mathrm{~h}$. On the other side, the decrease of lightning activity from 17:00 UTC is slower, occurring in about $14 \mathrm{~h}$, while convection typically moves slightly from the mountain to coastal areas, as it will be described in the next sub-section. Since the frequency of lightnings provides a measure of the probability of the occurrence of convection, the mean diurnal cycle of lightning is in agreement with the $6 \mathrm{~h}$ climatology of thunderstorms in the smaller domain, which includes just the Friuli Venezia Giulia region, by Manzato (2007) (his Fig. 2), while the time of the maximum peak found by Gladich et al. (2011) is shifted later (at 19:00 UTC, in their Fig. 3). Thunderstorms being more frequent during the afternoon and less frequent during the morning have also been observed in other European areas like Czech Republic (Novák and Kyznarová, 2011), Romania (Antonescu and Burcea, 2010) and Finland (Tuomi and Mäkelä, 2008).

\subsection{Spatial distribution}

The spatial distribution of $\mathrm{C} 2 \mathrm{G}$ lightnings displayed in Fig. 3 is the mean value considering the total number of flashes for all the $17 \mathrm{yr}$ analyzed. From this figure, the lightning distribution seems to be topographically influenced, depicting a decrease in the flash rates with the topographic height. This argument will be further discussed by the authors in a following article. As discussed previously, the "active period" starts in April with some $\mathrm{C} 2 \mathrm{G}$ lightnings observed in the Prealpine region (Fig. 6a). By the month of May the flashes become more frequent in the same region and also in the surrounding areas, gradually increasing while approaching the summer season (Fig. 6b-c). The maximum activity occurs during July and August (Fig. 6d-e), extending from the foothills area to the plane and affecting also the coastal areas in the late summer (starting from August). Since September, the main active area moves from land to the sea and on the coastal regions of NE Italy and Croatia's islands, fading thereafter (Fig. 6f-h). In general, it is clear that in spring-summer the largest occurrence of lightnings is over land, whilst in autumn the situation is reversed and the peak values are seen over coastal areas and on the sea, when thunderstorms are influenced by the warm sea and the strong land-sea gradients. These local maxima are mainly due to the Adriatic Sea, which supplies warm and humid air, thus increasing the convection probability, especially during the autumn when this effect is the strongest (as observed in the relative maximum in November in Fig. 5b). This is in agreement with the general study of lightning characteristics in Europe by Holt et al. (2001). 
a

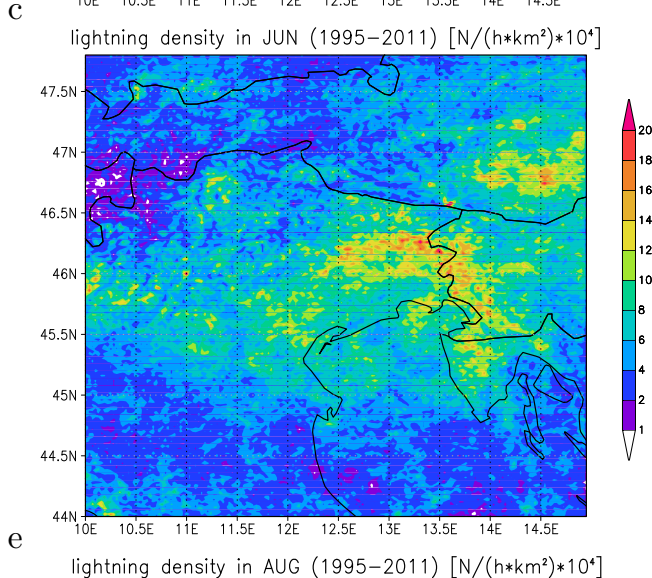

e
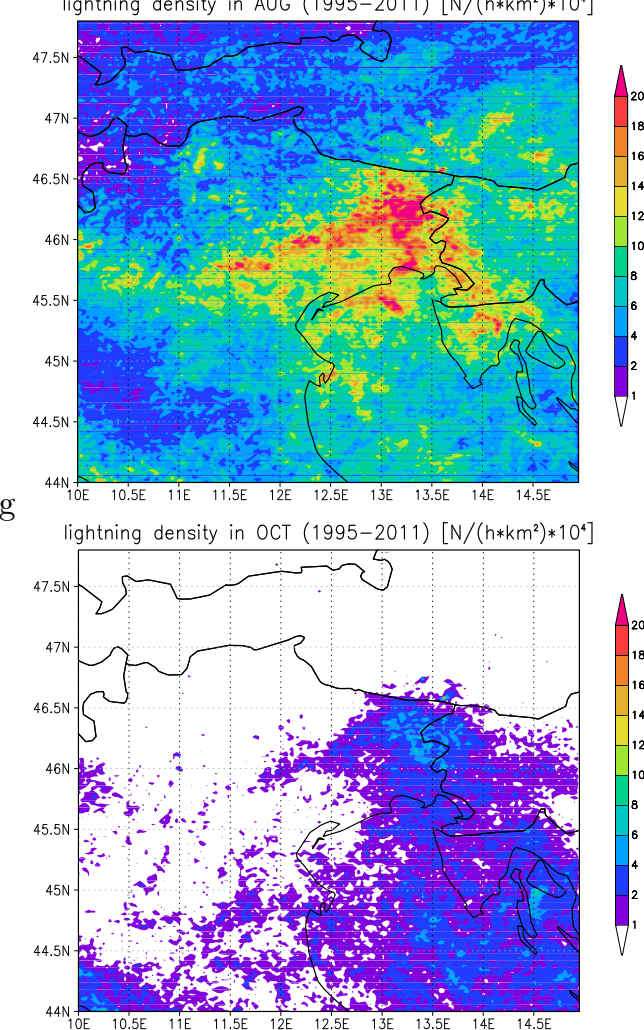

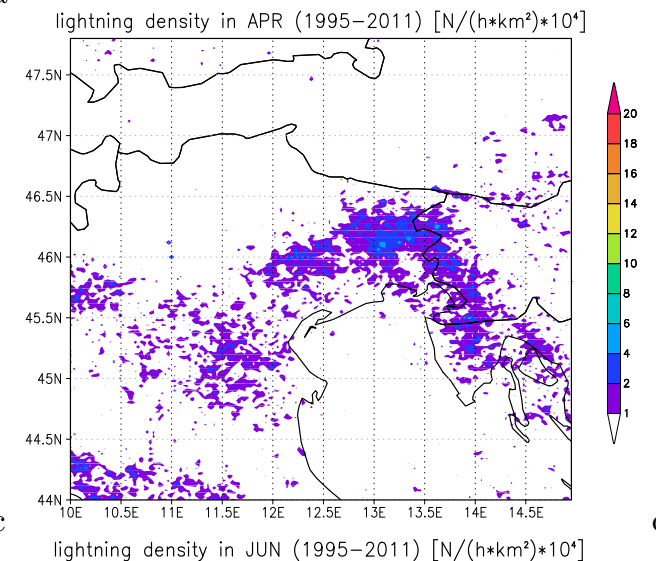

$\mathrm{d}$

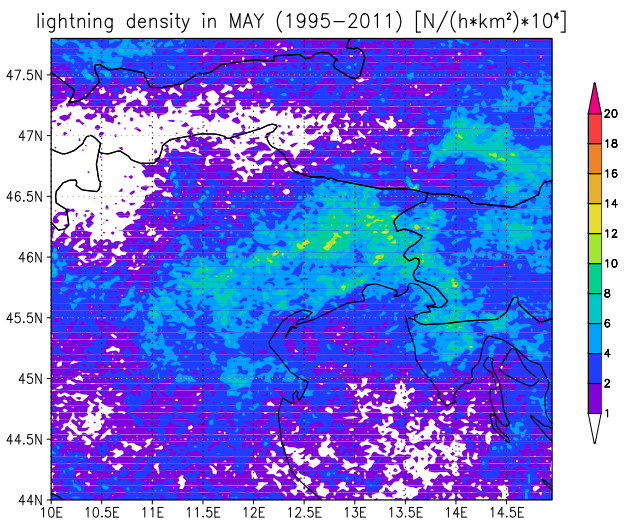

f
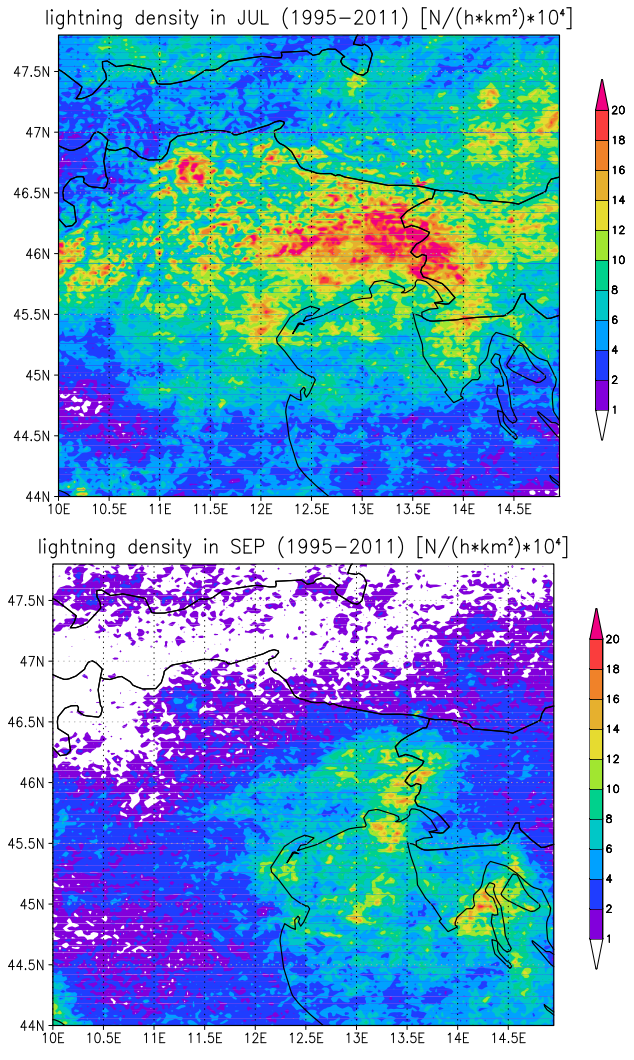

$\mathrm{h}$

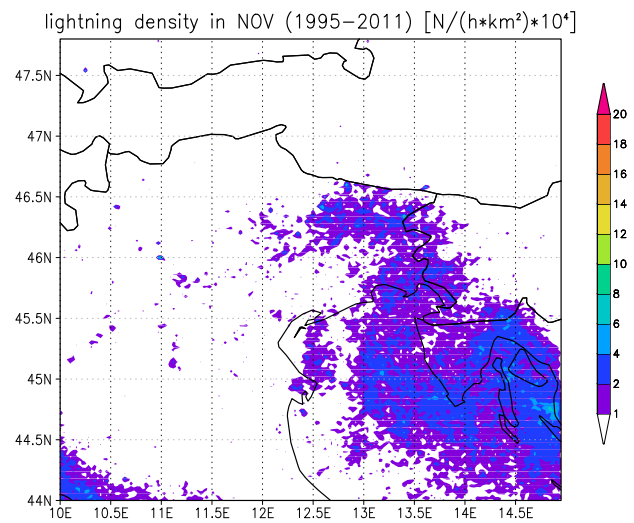

Figure 6. Month-by-month $\mathrm{C} 2 \mathrm{G}$ lightning spatial distribution starting from April up to November. The scale is number of lightnings per hour per $\mathrm{km}^{2}$ times a factor of $10^{4}$. 


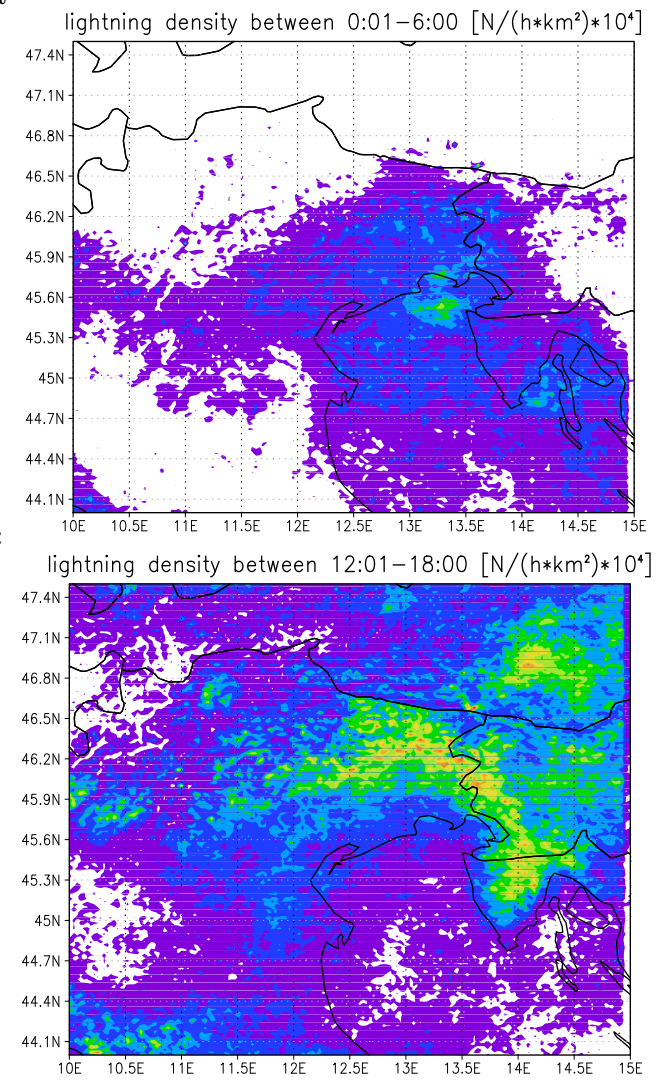

$\mathrm{b}$

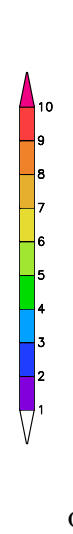

$\mathrm{d}$

lightning density between 6:01-12:00 $\left[\mathrm{N} /\left(\mathrm{h} * \mathrm{~km} \mathrm{~m}^{2}\right) * 10^{4}\right]$
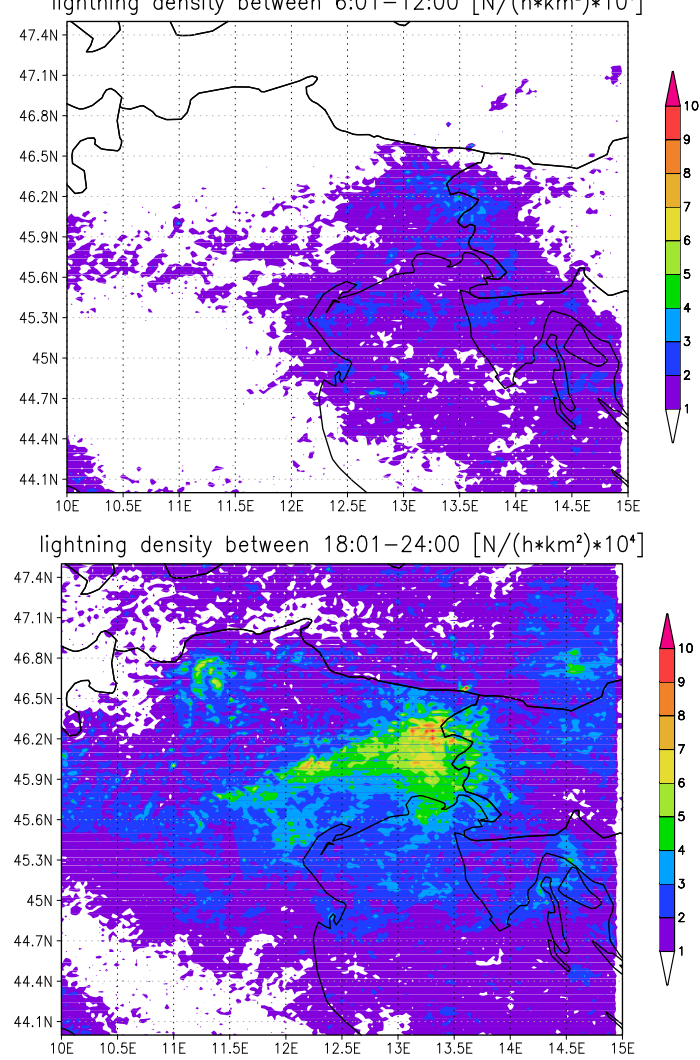

Figure 7. Daily cycle spatial distribution of C2G lightning: (a) 00:00-06:00 UTC, (b) 06:00-12:00 UTC, (c) 12:00-18:00 UTC and (d) 18:00-24:00 UTC. The peak is in the afternoon over land moving than to the coastal area and the sea during the night. Units are number of flashes per hour per $\mathrm{km}^{2}$ times a factor of $10^{4}$.

The diurnal cycle of $\mathrm{C} 2 \mathrm{G}$ flashes also displays different patterns depending on the time of the day. Because of complex terrain in north-eastern Italy, with mountain-valley areas in the Alps and Prealps, and with the plain being surrounded by the high-terrain of the Alps (with peaks exceeding the $3000 \mathrm{~m}$ ) in the North and delimited by the Adriatic Sea on the South, the domain is affected by mountainvalley breezes and land-sea breezes, which may trigger convection. Figure 7 shows the migration of thunderstorms, as recorded by the observed flashes, with the diurnal cycle. This figure highlights the different distribution patterns in the four $6 \mathrm{~h}$ periods of the day: the peak occurs between 12:0018:00 UTC (Fig. 7c), with the highest density of flashes in the Julian Prealps down to Istria; from the evening to nighttime (18:00-24:00 UTC) the peak moves to the foothill area of the Carnic-Julian Prealps, and some activity is observed also on the sea area usually more affected by nocturnal thunderstorms (Fig. 7d). Between the night and the first hours of the day (00:00-06:00 UTC) most of the flashes are recorded on the sea and along the coast (Fig. 7a), due to the nighttime inland radiation cooling and corresponding cold drainage air masses. As expected from Fig. 5c, the minimum rate of $\mathrm{C} 2 \mathrm{G}$ flashes occurs during the morning, in the $6 \mathrm{~h}$ period between 06:00 and 12:00 UTC (Fig. 7b).

\section{Conclusions}

This work focuses on the $\mathrm{C} 2 \mathrm{G}$ lightning climatology for the north-eastern part of Italy. Approximately 6.5 million $\mathrm{C} 2 \mathrm{G}$ lightnings (both negative and positive), recorded in this area between 1995 and 2011, were analyzed in the spatial and temporal scale, in order to identify the areas prone to high rates of $\mathrm{C} 2 \mathrm{G}$ flashes. The main conclusions are that, with respect to the domain investigated in this work and that used by Schulz et al. (2005), it appears that the Friuli Venezia Giulia region is the area in Central Europe with the maximum of lightning density, reaching values as high as 9.6 lightnings per $\mathrm{km}^{2}$ per year. Moreover, the spatial distribution of C2G lightnings is influenced by the topography, such that the gridboxes with maximum lightning density correspond to the tops of some Julian Prealps mountains (or particularly high towers).

C2G lightning activity shows a seasonal cycle with the active period starting in April and continuing up to October, 
with maximum probability occurring mainly in the Carnic and Julian Prealps. A smaller peak occurs also along the coastal areas in November, due to the unstable conditions induced by the North Adriatic Sea, warmed up during the previous summer season. The seasonal cycle modulates a daily cycle which clearly shows strong lightning activity in the afternoon in the mountain region, fading from the night while moving to the sea. The database analyzed shows that there is an overall tendency to an increase in $\mathrm{C} 2 \mathrm{G}$ lightning frequency, but the trend is not statistically significant. An evaluation of the relationship of $\mathrm{C} 2 \mathrm{G}$ lightning distribution with the topography will be the topic of a further article by the authors.

Acknowledgements. This research was carried out under the support of the project 2CE120P3 INCA-CE, funded by the program ETC Central Europe FESR funds.

Edited by: M. Dolinar

Reviewed by: two anonymous referees

\section{References}

Antonescu, B. and Burcea, S.: A cloud-to-ground lightning climatology for Romania, Mon. Weather Rev., 138, 579-591, 2010.

Ashley, W. S. and Gilson, C. W.: A Reassessment of U.S. Lightning Mortalities, B. Am. Meteorol. Soc., 10, 1501-1518, 2009.

Bernardi, M. and Ferrari, D.: Evaluation of the LLS efficiency effects on the ground flash density, using the Italian lightning detection system SIRF, J. Electrostatics, 60, 131-140, 2004.

Curran, E. B., Holle, R. L., and Lopez, R. E.: Lightning Casualties and Damages in the United States from 1950 to 1994, J. Climate, 13, 3448-3464, 2000.
Finke, U. and Hauf, T.: The characteristics of lightning occurrence in southern Germany, Inst. für Physik der Atmosphäre, 1996.

Gladich, I., Gallai, I., Giaiotti, D., and Stel, F.: On the diurnal cycle of deep moist convection in the southern side of the Alps analysed through cloud-to-ground lightning activity, Atmos. Res., 100, 371-376, 2011.

Haiden, T., Kann, A., Wittmann, C., Pistotnik, G., Bica, B., and Gruber, C.: The Integrated Nowcasting through Comprehensive Analysis (INCA) system and its validation over the Eastern Alpine region, Weather Forecast., 26, 166-183, 2011.

Holt, M., Hardaker, P., and McLelland, G.: A lightning climatology for Europe and the UK, 1990-99, Weather, 56, 290-296, 2001.

Kilinc, M. and Beringer, J.: The spatial and temporal distribution of lightning strikes and their relationship with vegetation type, elevation, and fire scars in the Northern Territory, J. Climate, 20, 1161-1173, 2007.

Manzato, A.: The $6 \mathrm{~h}$ climatology of thunderstorms and rainfalls in the Friuli Venezia Giulia Plain, Atmos. Res., 83, 336-348, 2007.

Novák, P. and Kyznarová, H.: Climatology of lightning in the Czech Republic, Atmos. Res., 100, 318-333, 2011.

Orville, R. and Huffines, G.: Cloud-to-ground lightning in the United States: NLDN results in the first decade, 1989-98, Mon. Weather Rev., 129, 1179-1193, 2001.

Rivas Soriano, L., De Pablo, F., and Tomas, C.: Ten-year study of cloud-to-ground lightning activity in the Iberian Peninsula, J. Atmos. Sol.-Terr. Phy., 67, 1632-1639, 2005.

Rorig, M. and Ferguson, S.: Characteristics of lightning and wildland fire ignition in the Pacific Northwest, J. Appl. Meteorol., 38, 1565-1575, 1999.

Schulz, W., Cummins, K., Diendorfer, G., and Dorninger, M.: Cloud-to-ground lightning in Austria: A 10-year study using data from a lightning location system, J. Geophys. Res., 110, D09101, doi:10.1029/2004JD005332, 2005.

Tuomi, T. and Mäkelä, A.: Thunderstorm climate of Finland 19982007, Geophysica, 44, 67-80, 2008. 